\title{
ACESSO À JUSTIÇA AMBIENTAL NO MARANHÃO: DESENVOLVIMENTO, SUSTENTABILIDADE E DISTORÇÕES NO TRATO JUDICIAL DAS CAUSAS AMBIENTAIS.
}

\section{ENVIRONMENTAL JUSTICE'S ACCESS IN MARANHÃO: DEVELOPMENT, SUSTAINABILITY AND DISTORTIONS IN THE JUDICIAL TREATMENT OF ENVIRONMENTAL CAUSES.}

\author{
${ }^{1}$ Regina Lúcia Gonçalves Tavares \\ ${ }^{2}$ Gregorio Mesa Cuadros
}

\section{RESUMO}

Este trabalho busca examinar a configuração da índole do direito de acesso à justiça ambiental, sob a perspectiva da sustentabilidade, tendo em vista as implicações decorrentes da relação natureza-sociedade, discutindo-se os direitos ambientais numa perspectiva de integralidade, a partir da superação de uma visão individualista dos direitos civis e políticos, caracterizadora de uma cultura jurídica normativista e técnico-burocrata, assim articulando a presente discussão a partir de decisões judiciais colhidas para ilustrar a perspectiva de desenvolvimento sustentável nelas utilizadas, analisando-se o quanto estas revelam, a título de fundamento, a base racional do mecanismo de mercado.

Palavras-chave: Sustentabilidade, Justiça ambiental, Acesso à justiça

\begin{abstract}
This paper seeks to examine the configuration of access to environmental justice's right and it's nature from the perspective of sustainability, in view of the implications about the relationship nature-society, discussing the environmental rights an integral perspective, from overcoming an individualistic view of civil and political rights, characterizing a normative and technical bureaucrat legal culture, thus articulating the present discussion from judicial decisions harvested to illustrate their perspective of sustainable development, analyzing how they reveal, with a view to explaining, the rational basis of the market mechanism.
\end{abstract}

Keywords: Sustainability, Environmental justice, Access to justice

\footnotetext{
${ }^{1}$ Mestranda em Direito e Instituições do Sistema de Justiça pela Universidade Federal do Maranhão - UFMA, Maranhão (Brasil). Professora pela Universidade Ceuma - Ceuma, Maranhão (Brasil). E-mail: rlg.t@ hotmail.com

${ }^{2}$ Doutor em Derecho pela Universidad Carlos III de Madrid - UC3M, Madrid (Espanha). Professor pela Universidade Federal do Maranhão - UFMA, Maranhão (Brasil). E-mail: gmesac@unal.edu.co
} 


\section{INTRODUÇÃO}

Cada ser humano tem sua própria compreensão de ambiente, pelo que tal conceito não pode ser reduzido a uma única concepção. Assim partindo-se do pressuposto de que a visão sistêmica de ambiente ${ }^{1}$ é a mais apropriada para o desenvolvimento das ideias aqui expostas, o presente trabalho busca estudar o trato do desenvolvimento sustentável, frente às teorias que envolvem a questão do acesso à justiça e a justiça ambiental, admitindo o desafio latente da contemporaneidade, qual seja o da busca por novos paradigmas principiológicos e conceituais, face ao contexto da modernidade em crise.

Considera-se o mecanismo do acesso à justiça como uma das alternativas de sustentabilidade e enfrentamento da crise ambiental pela qual passa a humanidade, num processo de se conjugar o homus economicus, com a preservação do ambiente em que este se acha inserido, e o papel essencial das instituições dos sistemas de justiça na tomada de decisões sobre o desenvolvimento sustentável ${ }^{2}$.

Por conseguinte, ao tratar do direito de acesso à justiça, busca-se ressaltar a pertinência de uma visão mais ampla do Direito, em detrimento do mecanismo de mercado que, no entendimento de Amartya Sen (SEN 2008, p. 136), não se mostra eficaz para a proteção de bens públicos, pelo que admitido o protagonismo dos princípios fundamentais, no enfrentamento das demandas ambientais, como ferramenta do desenvolvimento sustentável, com destaque aos princípios da eficiência, da responsabilidade ambiental e da adequação.

No conjunto das espécies de ações que permitem o acesso à justiça ambiental, traz o presente estudo, achados jurisprudenciais que retratam demandas ambientais, revelando a maneira peculiar com que as mesmas são enfrentadas pelo poder jurisdicional, no que tange às racionalidades lá concebidas acerca da sustentabilidade.

Muito embora a análise pontual dos casos em estudo não permita conclusões generalísticas acerca da concepção da sustentabilidade adotada pelas decisões judicias em causas ambientais, é possível identificar que aquelas decisões ostentam uma forma de pensar que torna possível compreender a base racional de mercado, não sustentável, sobre a qual se reproduz a jurisprudência em matéria ambiental.

\footnotetext{
${ }^{1} \mathrm{O}$ direito ambiental é hoje um sistema de normas determinadas pela expectativa e pressão social em direção a um ambiente adequado e, simultaneamente, um registro de saber histórico próprio da dogmática jurídica. (tradução minha) (SERRANO MORENO, 1998, apud MESA CUADROS, 2013, p.95)

2 A definição de desenvolvimento sustentável, encontrada no Relatório Brundtland, é que o imperativo econômico convencional, maximização da produção econômica, deve ser restringido em favor dos imperativos sociais (minimização do sofrimento humano atual e futuro) e ecológicos (de proteção da ecosfera). $O$ desenvolvimento sustentável depende então de reduzir a destruição ecológica, principalmente através da diminuição das trocas de energia e matéria-prima dentro da economia. (BELLEN, 2003, p. 72-73)
} 
Por meio de uma abordagem qualitativa da análise de decisões judicias e dos conceitos definidos em legislação pertinente, associando o conteúdo da norma e a teoria aplicável à espécie, procede-se a análise destas decisões e da principiologia a ela pertinente, a partir de pesquisa bibliográfica apta a fundar um marco teórico sobre a discussão a ser implementada, sintetizando-lhes informações, verificando tendências e construindo constatações acerca do acesso à justiça ambiental, considerando que o objeto de estudo deve ser abordado qualitativamente, vez que não se trata de dado neutro, mas rico de significados.

Assim, é este artigo estruturado inicialmente por uma abordagem teórica sobre o acesso à justiça ambiental e a ética do desenvolvimento, compreendendo-se os direitos ambientais numa perspectiva de integralidade.

Adiante, buscando-se a dimensão conceitual do princípio da eficiência com vistas a socorrer o trato sustentável das causas ambientais, faz-se um apanhado sobre as espécies de ações previstas no cenário jurídico brasileiro, para a persecução destes direitos.

Após a análise de questões pertinentes ao acesso à justiça ambiental, faz-se a apreciação de decisões proferidas, respectivamente, em ação civil pública ajuizada pelo Ministério Público, e em ação de mandado de segurança proposta por um particular, contra o Secretário de Meio Ambiente e Recursos Naturais do Estado do Maranhão, ambas apresentadas ao Tribunal de Justiça do Estado do Maranhão, comparando-as com outras decisões de âmbito nacional e ainda confrontando-as com perspectivas conceituais, na análise de um Estado ambiental de Direito sustentável.

\section{ACESSO À JUSTIÇA AMBIENTAL E A ÉTICA DO DESENVOLVIMENTO}

Autores como Cappelletti e Garth (CAPPELLETTI E GARTH, 2002, p.11) compreendem o direito de acesso à justiça como aquele inerente aos direitos individuais e sociais, cuja titularidade só é dotada de sentido quando resguardada por mecanismos de reivindicação.

Pode-se, com propriedade, situar o direito de acesso à justiça no campo dos direitos humanos, isto porque sua percepção científica contemporânea há muito já ultrapassou a concepção liberal de pensá-lo como um direito de realização tipicamente formalista, dogmática e alheia às realidades de sua respectiva conjuntura social.

Necessário, pois, estar face-à-face com uma compreensão de que novas epistemologias devem vir tomar o lugar daquela perspectiva positivista, já que, segundo aponta Antônio Carlos Wolkmer (WOLKMER, 2010, p 21), esta postura não mais 
acompanha as transformações sociais e econômicas do tempo da moderna sociedade política, o que requer, preponderantemente, a necessidade de repensar o Direito como hábil mecanismo pelo qual se pode construir uma sociedade sustentável, mais humana e mais justa, pela alteração das práticas vigentes, tais como aquelas relacionadas à justiça e o ambiente.

Naturalmente, o direito de acesso à justiça encontra-se em posição de avanço, isto considerando o limite liberal do individualismo proprietário lockeano (MESA CUADROS, 2013, p. 68), a evidenciar a trajetória do pensamento jurídico-sociológico que, neste novo contexto, deixa de estudá-lo exclusivamente como mecanismo de resguardo de direitos individuais, mas redefine seu objeto de proteção, segundo os novos paradigmas do que ainda chamamos de modernidade.

Volta-se à equação de mecanismos que permitam a proteção de direitos sociais e de solidariedade e, caso da América Latina e outros países periféricos, a reengenharia dos sistemas de acesso à justiça, pensado como meio de superação dos obstáculos econômicos, sociais e culturais que afetam sua efetivação (SANTOS 2013, p. 208), selando-se uma relação de compromisso com o processo de democratização para um desenvolvimento do direito e da sociedade, sob padrões mais humanitários.

Como complexa é a configuração da índole do direito de acesso à justiça, sob a perspectiva da sustentabilidade, complexo é se conjecturar sobre da sociedade moderna ${ }^{3}$, pelo que, fatores como o aumento da densidade demográfica, e consequente artificialização das relações sociais, favorecem sobremaneira o surgimento e a sofisticação dos conflitos postos sob a apreciação do Estado, num recorte de seu enfrentamento formal jurisdicionalizado, especialmente no que se refere a conflitos originados da relação entre os ecossistemas e o panorama cultural humano e de como se dialoga com esta inter-relação, a partir do que é permitido e do que é proibido.

Pela compreensão do direito como o produto cultural de uma escalada histórica do gênero humano e de suas relações com seus iguais e com o ambiente, este se apresenta em múltiplas dimensões (MESA CUADROS 2013, p. 70), pelas quais o ambiente não pode ser reduzido a uma só concepção, vez que todos os direitos são, assim, direitos ambientais, vistos sob uma perspectiva integral dos direitos, em oposição a uma concepção liberal e positivista, já que inter-relacionados por critérios de diversidades natural e cultural.

\footnotetext{
${ }^{3}$ Nas palavras de Ramos: "Essa caminhada não é fácil, mas o primeiro passo pode ser dado a partir da compreensão do jogo de poder que se dá na sociedade, a parir do momento em que se compreenda o porquê de as instituições criadas para resguardar direitos não conseguir protegê-los" (RAMOS, 2012, p.45)
} 
Abordando-se a questão do acesso à justiça dentro de uma perspectiva de justiça ambiental sustentável, discutem-se os direitos ambientais nesta perspectiva da integralidade, ao reconhecer-se que uma das maiores riquezas desta abordagem é a superação de uma visão individualista dos direitos civis e políticos.

O ambiente deve ser concebido como um processo de permanente tensão e mudanças, ocasionadas pela intervenção humana de diversos tipos (MESA CUADROS, 2013, p. 70), - assim consideradas aquelas realizadas sob uma perspectiva de sustentabilidade, como aquelas que o depreciam e o degradam - onde o foco dos problemas ambientais não deve se restringir a uma visão estritamente ecológica, mas na noção de que o problema ambiental, ultrapassada esta questão natural, envolve igualmente aqueles gerados pelos seres humanos, suas culturas e formas de desenvolvimento dentro de suas relações com a biosfera.

Depreende-se de tal concepção, que os direitos ambientais passam a ser vistos como uma mescla de múltiplos elementos que se relacionam dinamicamente e que integram o conceito de justiça ambiental: elemento jurisdicional, elemento social e humano e elemento espacial e econômico (BELLMONT, 2011, p. 65). Eles trazem um novo olhar sobre os direitos ambientais e fazem compreender que a relação do homem com o ambiente não mais deve ser abreviada a um mecanismo de redução de possibilidades (os direitos estandardizados sob uma perspectiva individualista e homogênea, que longe de emanciparem, legitimaram a servidão).

Retomando a compreensão da escalada evolutiva dos direitos de primeira e segunda geração (direitos individuais e direitos sociais), compreende-se que os direitos de solidariedade, de terceira geração, inauguram uma nova epistemologia acerca da dialética dos direitos da mulher e do homem, vistos não mais restritos às relações entre indivíduos e Estado, mas numa ampla perspectiva de relação dos povos que formam a humanidade e o planeta terra, suas culturas e respeito às suas ancestralidades (ROULAND 2008, p. 269). O homem, a partir de sua individualidade, não mais reconhecido como o grande legislador do universo.

Historicamente, a concepção de propriedade privada, sob inspiração liberal e positivista, reconhece a projeção do indivíduo sobre as coisas, permitindo identificar tal perspectiva hegemônica de justificação da apropriação dos recursos ambientais pelo trabalho ${ }^{4}$,

\footnotetext{
${ }^{4}$ Para Locke, a propriedade já existe no estado de natureza e, sendo uma instituição anterior à sociedade, é um direito natural do indivíduo que não pode ser violado pelo Estado. $\mathrm{O}$ homem era naturalmente livre e proprietário de sua pessoa e de seu trabalho. Como a terra fora dada por Deus em comum a todos homens, ao incorporar seu trabalho à matéria bruta que estava em estado natural o homem tornava-a sua propriedade privada, estabelecendo
} 
com poder de autoridade dada pelo Estado, mediante honesta veneração ao ordenamento jurídico produzido por uns em detrimento de muitos, que cria o Estado e ao mesmo tempo por ele é criado, num sistema que se retroalimenta, o que torna a natureza um bem à disposição da cobiça humana, que poderá dela apropriar-se conforme sua conveniência (BELLMONT, 2013, p. 91).

Contextualizada esta discussão ante a questão da concepção da propriedade, na conjuntura histórica da América Latina, tem-se que, por ocasião da chegada dos Europeus, a partir do século XVI, a empreitada de apropriação da terra americana pelo colonizador legitimou uma concepção de que a América era terra de ninguém (TOCQUEVILLE 2005, p.

384), e que a titularidade de seus domínios deveria ser concebida a partir de sua noção eurocêntrica de trabalho e propriedade, segundo a visão dos Contratualistas, por isto, plenamente justificado o assentamento do colono em lugar das tribos indígenas, vistas como pouco afetas à lida com a terra, para que se seguisse um pretendido eficaz aproveitamento de seu potencial de riqueza.

O contrato social fundador da modernidade foi celebrado para proteger o indivíduo das ações de seus semelhantes, contudo, o referido pacto reduziu os direitos do gênero humano a partir de uma perspectiva antropocêntrica de sua existência, pelo que excluída deste ato simbólico qualquer aliança com a natureza.

Evidentemente, a ação intermitente do ser humano, em legitimar sua apropriação dos recursos naturais, a partir da perspectiva de empoderamento pelo trabalho e o esgotamento dos recursos ambientais devido ao seu uso nocivo, fez nascer a necessidade de criação de vínculos de direito que limitassem ou, ao menos, regulamentassem a ação do homem sobre o planeta Terra, permitindo o desenvolvimento econômico das gerações sob uma ótica de sustentabilidade, a fim de garantir a incolumidade desta e das futuras gerações.

Por conseguinte, no caso da América Latina, quanto às tutelas jurídicas dos direitos ambientais, estas se manifestam tomando por base todo um sistema jurídico permeado de valores selecionados por dada sociedade (e, caso da justiça ambiental, destaca-se: natureza, ambiente, sustentabilidade, dentre outros) repousados sobre um Estado cuja estrutura política acha-se sedimentada sobre os valores liberais secularmente construídos num processo de colonização tanto do ambiente, quanto das ideias: uma sociedade cuja ideia de desenvolvimento traduz-se pelo conceito de mercado e suas viabilidades econômicas. 
A economia-ciência tradicional, com efeito, não considera quaisquer conexões que possam existir entre o sistema ecológico e as atividades de produzir e consumir que representam o cerne de qualquer sistema econômico (economia-atividade). O modelo econômico típico não contempla a moldura ou restrições ambientais. Cuida de focalizar tão somente fluxos e variáveis do domínio econômico. (CAVALCANTI, 2010, p. 53)

Nesta ótica, Amartya Sen (SEN, 2008, p. 152) adverte para a necessidade de uma ação de suplementação deste mecanismo de mercado, que não se mostra eficaz quanto à proteção de bens públicos, como é o caso da preservação ambiental, cujos efeitos de uma ação não sustentável produzem um ambiente que teremos que consumir juntos, independentemente de nossas influências de negociação e respectivos estados de desenvolvimento.

Uma das suposições tradicionalmente feitas para demonstrar a eficiência do mecanismo de mercado é a de que todo bem - e, de um modo mais geral, tudo aquilo que o nosso bem-estar depende - pode ser comprado e vendido no mercado. Tudo se pode comercializar (se quisermos colocar no mercado), e não existe nenhuma influência que seja "não-negociável e significativa sobre nosso bem-estar. Na verdade, porém, alguns dos mais importantes elementos que contribuem para a capacidade humana podem ser difíceis de vender exclusivamente para uma pessoa de cada vez. Isso se aplica em especial quando consideramos os chamados bens públicos, que as pessoas consomem juntas, e não separadamente. (SEN, 2008, p.

A importância da ideia de justiça tem seu conteúdo refinado e seu alcance ampliado a partir do exercício de um exame crítico de sua argumentação racional (SEN 2014, p. 436), muito embora tais análises não levem a um juízo conclusivo: "vamos até onde podemos razoavelmente ir".

As decisões judicias, colhidas para ilustrar a perspectiva de desenvolvimento sustentável nelas utilizadas, são aptas a revelarem a base racional do mecanismo de mercado, onde o processo, em matéria ambiental, finda por servir de instrumento a esta racionalidade, questionável quanto à sua eficiência, segundo o exame das exigências de justiça e a insustentabilidade do desenvolvimento que ela promove.

\section{JUSTIÇA AMBIENTAL: eficiência e sustentabilidade no trato de bens públicos}

A ideia que o homem faz do direito depende do sentido que ele dá ao mundo (ROULAND, 2008, p. 61), pelo que a apropriação do capital pela ordem internacional, de índole globalizante e neoliberal, demanda do Direito a necessidade de desafiar os instrumentos legitimadores da apropriação individualista, para que sejam pensados 
mecanismos que viabilizem um diálogo democrático acerca dos problemas decorrentes das questões ambientais e do desenvolvimento sustentável.

No panorama da eficiência da justiça ambiental, transcender o tema de sua distribuição e redistribuição, passa pela estratégia de reconhecimento de diferenças, estabelecendo-se uma postura de análise bivalente das origens culturais e econômicas das diversas injustiças, em busca de soluções eficientes de sustentabilidade (BELLMONT 2013, p. 104).

A Constituição da República Federativa do Brasil de 1988, marco normativo inaugural da atual experiência de Estado Democrático de Direito no Brasil, no artigo 37, consagra o princípio da eficiência como princípio administrativo, vetor hermenêutico da atuação de qualquer dos Poderes, inclusive do Poder Judiciário. Não bastasse sua previsão constitucional, ainda no âmbito jurisdicional, o princípio da eficiência recebe estatura de norma fundamental do processo, no artigo $8^{\circ}$, do Código de Processo Civil brasileiro (Lei $\mathrm{n}^{\circ}$ 13.105, publicada em 16/03/2015).

A dimensão do princípio da eficiência dentro do aspecto da atividade jurisdicional é uma versão contemporânea e também atualizada do princípio da economia processual (DIDIER JR, 2015, p. 101), como zelo retórico de prescrever ao juiz a função de administrador do processo e estabelecer metas a serem alcançadas para obtenção máxima de um fim, com um mínimo de recursos, atendendo os fins do processo de maneira satisfatória, em termos quantitativos e qualitativos, de modo minimamente intenso.

Convém dar esta precisão conceitual ao princípio da eficiência, como termo substitutivo da economia processual, ante a necessidade de precisar a distinção entre eficiência e efetividade. É efetivo o processo que reconhece o direito afirmado pelo postulante e eficiente o processo que o faz de maneira satisfatória (DIDIER JR., 2015, p. 103), numa perspectiva de qualidade da prestação jurisdicional (administração do processo, redução de custos e de tempo). Portanto, conclui o referido processualista que o processo efetivo nem sempre será eficiente, mas jamais poderá ser eficiente sem ter sido efetivo.

Vista sob este parâmetro de eficiência, a justiça ambiental, relacionada ao manejo das ações judiciais, como ferramenta de proteção dos direitos ambientais e da sustentabilidade, constitui-se não só sob o aspecto procedimental, com a definição, pela legislação pertinente, de instrumentos processuais que viabilizam o acesso à justiça e a apresentação da respectiva demanda ambiental. 
Porquanto, tem-se a corroborar com os elementos de compreensão da justiça ambiental, a postura dos operadores judiciais no que tange ao manejo, interpretação, aplicação e materialização da norma de natureza ambiental. Assim, faz-se necessário que o processo civil alcance a legitimidade necessária a torná-lo instrumento de exercício da jurisdição. "E para isso é preciso que sejam legítimos não só os fins a que se destina o processo civil, mas também os meios de que se vale para alcançá-lo". (CÂMARA, 2013, p. 70)

A Política Nacional do Meio Ambiente, seus fins e mecanismos de formulação e aplicação, disposta na Lei 6.938, de 31 de agosto de 1931, define, dentre outras coisas, a obrigação do poluidor de indenizar danos ambientais que vier a causar, independentemente de culpa, bem como autoriza o órgão do Ministério Público a propor ações de responsabilidade civil por danos causados ao ambiente, demandando acerca da recuperação, bem como da respectiva indenização em relação aos prejuízos causados.

A ação civil pública de que trata a referida norma tem previsão constitucional no artigo 129, III, da Constituição Federal, sendo regulamentada pela Lei no 7.347/95, e seu objeto abrange direitos coletivos em sentido amplo, neste conjunto inserido o direito a um ambiente são, e tem por objeto a condenação em dinheiro ou o cumprimento de obrigação de fazer ou não fazer, apurada após instrução probatória de índole comum.

Trata-se de um veículo processual pelo qual é possível defender interesses supraindividuais, no sentido de tutelar o ambiente, cuja legitimidade para sua propositura acha-se prevista no artigo $5^{\circ}$ da aludida Lei.

Além da ação civil pública, como mecanismo procedimental de acesso à justiça ambiental, a legislação brasileira também admite que sejam postulados aqueles direitos por meio de ação de mandado de segurança, constitucionalmente prevista no artigo $5^{\text {a }}$, inciso LXIX, da Constituição Federal, regulamentada pela Lei $\mathrm{n}^{\circ} 12.016 / 09$, sendo remédio jurídico constitucional destinado à proteção de direito individual e coletivo líquido e certo, ou seja, aquele direito que já vem definido expressamente em norma legal e que verse sobre fatos que se tornem incontroversos pela simples interpretação do aludido direito (TEMER, 2010, p. 190), pelo que impertinente, nas ações de mandado de segurança, qualquer instrução processual que desnature seu estreito limite cognitivo.

Segue-se, na lista de procedimentos judicias sobre os quais se pode postular demandas de natureza ambiental, a ação popular, constitucionalmente prevista no artigo $5^{\text {a }}$, inciso LXXIII, da Constituição Federal, regulamentada pela Lei no 4.717/65. Esta ação constitucional de natureza civil é atribuída a qualquer cidadão que, em nome próprio 
(NOHARA, 2011, p. 832), visa invalidar atos ou contratos administrativos que causem lesão ao patrimônio público ou ainda à moralidade administrativa, ao patrimônio histórico e cultural e ao ambiente, possuindo limites de cognição voltados à anulação de ato do poder público que venham a lesar, por exemplo, o ambiente, e, por esta razão, pouco utilizada para tal finalidade.

Por fim, compreendendo que, das relações do gênero humano entre si e deste com o ambiente, podem resultar as mais variadas espécies de situações que demandam a proteção estatal, configurada pelas instituições do sistema de justiça, especialmente o Poder Judiciário, sobretudo diante da garantia inscrita no artigo $5^{\circ}, \mathrm{XXXV}$, da Constituição Federal, de que nenhuma lesão, ou ameaça de lesão, poderá ser excluída da apreciação da jurisdição estatal, mencione-se a possibilidade demandar, em matéria ambiental, mediante o ajuizamento de ações de procedimento comum que, ordinariamente, instrumentalizem o manejo desses direitos.

\section{A SIMBOLOGIA DAS DECISÕES ANALISADAS}

Após a análise de questões pertinentes ao acesso à justiça ambiental - e a necessidade de se ir além das regras de mercado no contexto da proteção do ambiente -, bem como acerca do princípio da eficiência do processo, assim considerando também sua efetividade, buscar-se-á, a partir da análise de pronunciamentos judicias, em demandas ambientais, reconhecer, na abordagem dada pelo julgador, a título de solução daquelas demandas, de que forma o princípio da eficiência foi manejado e, por conseguinte, em que medida tal princípio, tendo ou não sido considerado, comprometeu a efetividade da solução dos litígios, com vista a um desenvolvimento sustentável.

\subsection{Da Apelação Cível movida em Ação Civil Pública de Obrigação de Fazer ${ }^{5}$}

Tratou-se de ação civil pública em que configuraram como partes o Ministério Público, na condição de autor, e um particular na condição de réu; ação esta movida com a finalidade de obrigar o réu a recolher rebanho de gado bubalino, de sua propriedade, criado por ele de forma extensiva em zona alagadiça (bacias lacustres, formadas por grandes planícies baixas localizadas na Baixada Maranhense, situadas a oeste e sudeste da Ilha de São Luís), com pagamento do dano patrimonial, de fundo ambiental, resultante daquela prática.

Aquela demanda retrata situação de dano ao ambiente, configurada pela criação extensiva de búfalos nos campos alagadiços maranhenses, que lá deixados soltos, só são

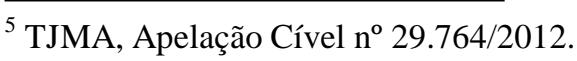


recolhidos por ocasião do abate, fato que traz séria consequência para o equilíbrio daquele ecossistema, já que o referido animal é dele elemento alheio, isto sem mencionar as consequências econômicas, sociais e políticas que sofrem os trabalhadores rurais que vivem e trabalham naquela região (MUNIZ, 2015, p. 2).

Assim uma vez proposta perante o juízo de direito da comarca de São João Batista, Maranhão, a referida ação civil pública foi extinta sem a resolução de seu mérito, por assim entender o julgador singular que não tinha o Ministério Público interesse de agir, ante a impossibilidade de se mensurar o dano ambiental ali discutido.

Recorrendo da decisão o Ministério Público, recebe do Tribunal o acolhimento de sua tese recursal para efeito de anular a sentença terminativa, com a devolução do feito para o juiz singular, a fim de que se desse o enfrentamento da matéria concernente ao seu mérito.

Entre um ato de tramitação processual e outro, a referida demanda foi apresentada ao judiciário em 21/10/2004, sendo despachada somente em 09/06/2011, ou seja, 2.422 dias após a primeira tramitação. Por conseguinte, remetida ao Tribunal de Justiça em 22/08/2012, por ocasião de apelação do Ministério Público contra sentença terminativa, esta somente foi julgada em 07/05/2013, segundo o que consta de sua ficha processual disponível no sítio eletrônico do Tribunal de Justiça do Maranhão.

Tomada a ação civil pública, ajuizada pelo Ministério Público, como aporte ilustrativo do presente trabalho, busca-se definir a postura do Estado frente às questões de natureza ambiental e em que medida sua atuação processual simbólica se dá em detrimento dos princípios da eficiência processual, da precaução e da responsabilidade ambiental, donde percebe-se a reprodução de uma ideologia que concebe o desenvolvimento a partir de sua vertente econômica, em desprestígio da justiça ambiental e seu contingente social e sem qualquer lastro de sustentabilidade.

Analisados estes dados sob a lente do princípio da eficiência, percebe-se que a sua não observância por parte do Estado, quando atua através de seu braço jurisdicional, corrobora com uma postura secular de negação dos direitos, quando produz atividade processual indigna de atender o reclame do jurisdicionado: a uma porque enfrenta a questão submetida a seu exame, sem vinculação a qualquer balizamento de critério temporal; a duas, porque o faz em pronunciamentos esvaziados de conteúdo de mérito, o que, por conseguinte, revela uma ideologia política em que a gravidade formal dos procedimentos finda por servir de obstáculo à plena realização do direito. 
Trata-se da expressão de uma tutela jurisdicional alheia aos fins do direito enquanto fenômeno que emerge dos valores e necessidades da sociedade, no que tange ao manejo do direito ambiental sob a ótica do desenvolvimento sustentável, portanto violadora de sua função instrumental:

Essa visão do fenômeno processual é absolutamente incompatível com a atitude passiva do magistrado, que não pode permanecer como mero assistente do "duelo" travado entre as partes, pois também o Estado tem interesse no resultado do processo, ainda que disponível o direito material. (BEDAQUE, 2013, p. 136)

Alexis de Tocqueville (TOCQUEVILLE, 2005, p. 112), quando analisa a formação política da América, compreende ser o juiz uma das primeiras forças políticas dos estados democráticos, porque, muito embora sendo árbitro que se posiciona sobre casos particulares somente quando chamado, tem reconhecido o direito de fundar suas decisões na Constituição, em vez de nas leis, permitindo-lhe deixar de aplicar aquelas que lhe parecerem inconstitucionais, dando, assim conteúdo político aos seus pronunciamentos e por via reflexa, ainda que por meio judiciários, ser o guardião da força originária de todos os poderes, o que não é pouca coisa.

Num estudo comparativo, colhe-se de decisão proferida pelo Tribunal de Justiça do Rio Grande do $\mathrm{Sul}^{6}$, por meio de Agravo de Instrumento interposto em Ação Civil Pública, ajuizada com o propósito de conter a realização de obra em área de preservação permanente, que aquele órgão julgador, diante da mesma dúvida acerca da extensão do dano em discussão, se posiciona de maneira diversa.

Para tanto, funda-se no princípio da precaução para, em proteção da sustentabilidade ambiental das atividades humanas, impor a remoção das obras, ali apontadas, porque realizadas em área de preservação permanente municipal, feitas sem o processo de licença ambiental, manifestando uma ratio decidendi articulada in dúbio pro natura, assim compreendendo ser de obrigação do suposto poluidor a prova de que a poluição não ocorreria.

Os princípios ambientais são critérios jurídicos, políticos-ambientais, que servem de vetores hermenêuticos para o aplicador e intérprete da norma. Decorre do princípio da responsabilidade ambiental a constatação de que o Estado age por omissão quando, devendo atuar para a proteção efetiva do ambiente, não o faz (MESA CUADROS, 2013, p. 134).

O princípio da precaução ambiental, contido na Declaração do Rio sobre Meio Ambiente e Desenvolvimento (MESA CUADROS, 2013, p. 137), prescreve aos Estados uma postura de que, diante da ameaça de danos graves ou irreversíveis, a ausência de certeza

${ }^{6}$ TJRS, Agravo de Instrumento No 70063996649. 
científica absoluta não poderá ser utilizada como razão para o adiamento de medidas economicamente viáveis para prevenir a degradação ambiental e a sustentabilidade das atividades humanas.

Reconhecendo que o Direito não pode se apartar da maleabilidade da vida, tem-se que a conjugação dos três princípios acima listados, seria fundamental para o tratamento do caso em estudo. Todavia, a ausência de ação política do judiciário, no sentido de seguir tal pauta principiológica, dá lugar a uma atuação estatal de proteção meramente formal ao direito ambiental: tramitação processual excessivamente lenta e um pronunciamento que, acanhadamente, deixa de enfrentar a questão de mérito por compreendê-la fora do alcance de sua cognição, assim desviando-se da aplicação do princípio da precaução, no âmbito da atuação jurisdicional e, consequentemente, descuidando da função de afastar do perigo a segurança das gerações futuras.

Surge da decisão em estudo que não se evidencia uma discussão racional para efeito de proteção do ambiente, desguarnecido por uma atuação judicial alheia aos seus fins sociais, ao passo que, ante a dúvida posta acerca da monta do alegado dano ambiental, ocorrido nos alagadiços da baixada maranhense, decidiu o juiz singular em favorecimento das atividades econômicas realizadas naquela local.

\subsection{Do Mandado de Segurança contra a ineficiência administrativa ${ }^{7}$}

Em outro achado jurisprudencial, este identificado por uma ação de mandado de segurança ajuizada por um particular contra o Secretário de Meio Ambiente e Recursos Naturais do Estado do Maranhão, perante o Tribunal de Justiça, o impetrante busca a concessão de segurança para que lhe seja dada a respectiva licença ambiental para projeto agrossilvopastoril, com aproveitamento de material lenhoso, para carvoejamento em uma área de sua propriedade, ou seja, autorização para desmate e licença operacional.

Motiva sua pretensão no fato de que, tendo solicitado as respectivas licenças à autoridade administrativa, esta não cuidou em respondê-lo tempestivamente, permanecendo silente quanto à concessão ou não da solicitada autorização, o que fez com que o Tribunal de Justiça acolhesse suas alegações, sob o fundamento de que a demora na apresentação da resposta por parte do administrador público ofenderia o princípio da eficiência, bem como da duração razoável do processo.

7 TJMA, Mandado de Segurança no $028392 / 2012$. 
Distanciando-nos do aspecto político da referida decisão e nos atendo exclusivamente a seus aspectos processuais, percebe-se que a atuação do julgador ultrapassa os limites estreitos da cognição, típica de uma ação de mandado de segurança, porque cabível em situações de lesão a direito que já venha expresso em lei e cuja subsunção aos fatos da causa não demandem atividade de investigação instrutória. Ou seja, para o caso em estudo, a concessão da segurança só se justificaria havendo lei que autorizasse a que aquele postulante explorasse aquela atividade, naquela circunstância.

A norma, geral e abstrata, não faria uma previsão nestes moldes tão específicos, de modo que a pretensão formulada demandaria uma ação investigativa. A concessão de uma licença para desmate, motivada exclusivamente na inércia da administração pública, sem o estudo de impacto ambiental que a respalde, demonstra que a jurisdição ambiental, em casos como este, não abarca a função de proteger o ambiente, vez que exerce uma proteção dissociada de limites sobre o direito de aceder aos ecossistemas, prestando, assim, um imenso desserviço à causa da sustentabilidade.

Ainda sob a perspectiva de um estudo comparado, o Tribunal Regional Federal da $4 .^{\text {a }}$ Região, julgando apelação interposta em face de sentença proferida por Juiz Federal de Curitiba, Paraná, impetrado contra ato do Superintendente do Instituto Brasileiro do Meio Ambiente e dos Recursos Naturais Renováveis - IBAMA ${ }^{8}$, negou a segurança lá requerida, para indeferir o pedido de reconhecimento da legalidade de atividade de pesca subaquática em locais onde são permitidas outras modalidades de pesca amadora no Estado do Paraná.

Fundou sua decisão, o Tribunal, na razão de que, a proibição então questionada, porque fundada em razões técnicas, careceria de instrução processual incompatível com os estreitos limites procedimentais do mandado de segurança.

Assim, um processo que reconhece um direito de uso do ambiente sobre o qual não se investigou, não é efetivo, assim não sendo efetivo, jamais poderá ser eficiente no compromisso de sustentabilidade, ainda que travestido na intenção de tutelar tal eficiência em relação à administração pública.

Fosse esta verdadeiramente a preocupação política do julgador, fá-lo-ia para determinar que a administração pública desse imediato seguimento ao processo administrativo que promoveria o respectivo estudo de impacto ambiental para concessão de licença ambiental para projeto agrossilvopastoril, a fim de não deixar mais o postulante sem resposta.

\footnotetext{
${ }^{8}$ TRF4, Apelação Cível Nº 5040752-09.2012.404.7000/PR.
} 
Porquanto, retornando ao aspecto político da decisão em análise, vê-se evidente que já não basta consignar o Direito em normas, mas trabalhar para que se construam mecanismos de proteção efetiva desses direitos, na busca de que o julgador assuma uma nova abordagem processual, sobretudo quando julga direitos ambientais, e não siga discriminando-o por razões meramente procedimentais.

\section{NOVAS PERSPECTIVAS PARA UM ESTADO AMBIENTAL DE DIREITO}

A sociedade contemporânea revela uma realidade identificada por Boaventura de Souza Santos (SANTOS, 2013, p. 164), de que a igualdade dos cidadãos perante a lei passa a ser confrontada com a desigualdade da lei perante os cidadãos, num contexto a acusar a crise na administração da justiça quando esta, conduzida segundo os parâmetros do liberalismo político, polariza o Estado em oposição à sociedade civil, não reconhecendo suas fragilidades, assim fragilizando-se, ao agir numa lógica de poder piramidal e alheia a uma atuação judicial criativa.

É certo que, a sofisticação do modus relacional do homem na sociedade, tanto em suas relações entre si, quanto à relação surgida a partir das interseções entre sua cultura e os ecossistemas, fizeram avançar nossa sociedade política em mais direitos, a exemplo dos direitos relacionados ao ambiente (CAPPELLETTI e GARTH, 2002, p. 33), contudo, mesmo reconhecidos esses novos direitos, evidente é a necessidade de pensar uma atuação estatal capaz de torná-los efetivos.

Se, por um lado, é compreendida a hegemonia e a importância do Direito produzido pelo Estado, de outro lado, ante a crescente complexidade de conflitos e a heterogeneidade socioeconômica, surge a necessidade de abordá-lo através de um pensamento crítico, não dogmático, pautado em valores do humanismo (valores capazes de nortear a conduta do homem, tais como igualdade, diversidade, liberdade de ideias, repúdio à violência, sustentabilidade etc), como paradigmas para uma nova cultura do direito (WOLKMER, 2010, p. 244), por meio de práticas emancipatórias de consensualismo, mediação, pluralismo jurídico e descentralização a superarem a ideia do Direito enquanto saber técnico, e posicioná- lo no conjunto das práticas sociais.

Provavelmente, esta nova epistemologia poderá desarmar esses descaminhos processuais que findam por comprometer severamente a eficiência e, por conseguinte, a eficácia dos direitos ambientais no sentido de sua sustentabilidade. 
Tanto a formação, quanto a atuação do judiciário, demandam uma ação que vai muito além de técnicas de atuação ditas econômicas, com vistas à eficiência do processo, e que resultam muito mais em crematística' - a que para o caso, chamaremos de 'crematística processual', em lugar de economia processual - que se distingue de economia ou eficiência processual porque, ao fazer-se um paralelo com o pensamento Aristotélico (TABOSA, 2007, p. 36), pode se afirmar que, enquanto esta última se relaciona com a ação-fim, num aspecto natural de se saber usar bem uma atividade, no sentido de torná-la eficiente, a outra cuida da produção, ou seja, preocupa-se com uma atividade-meio antinatural, para a produção de numerário, alheia aos propósitos do direito ao desenvolvimento sustentável.

A Teoria da Argumentação Jurídica (ALEXY, 2013, p 205), como uma teoria do discurso jurídico pela sua justificação racional, objetiva a cientifização do direito, necessária, a sua vez, à solidez de um Estado Democrático de Direito e, consequentemente, à legitimação dos pronunciamentos judicias daí decorrentes.

Assim, para Alexy, o discurso jurídico racional precisa se estabelecer para além da formulação de meras opiniões, mas ser construído racionalmente, tanto no aspecto formal (regras da lógica do discurso e sua semântica), quanto no aspecto material (o próprio conteúdo das normas), a fim de que ganhe uma pretensão de inteligibilidade, sendo capaz de satisfazer a necessidade de que a decisão judicial tenha consistência e, portanto, seja dotada de legalidade e legitimidade.

Porquanto, é o discurso jurídico uma atividade linguística, guiada por regras em que se objetiva a correção dos enunciados, onde o autor do discurso busca a aplicação correta do direito em conexão com a moral (ALEXY, 2013, p. 284), por isto consistente, tendo em vista a porosidade da lei positiva, apta a absorver um discurso com pretensão de correção, que é pretensão de justiça, mediante a explicação racional dos enunciados.

Trata-se de uma ótica a trazer outras perspectivas para um estado ambiental de direito, subvertendo a ideia de que para equacionar o problema do acesso à justiça ambiental, basta pensá-lo pela sua exteriorização jurídica, numa redefinição de papeis, num “comportamento ético, relacionado às normas que favorecem o meio ambiente" (SEN, 2008,

\footnotetext{
9 “Aristóteles estabelece uma distinção fundamental entre a economia e a crematística. A economia é uma ciência prática, um saber relacionado a uma ação, enquanto a crematística é uma arte poiética ou produtiva, de classe inferior, relacionada a uma produção. A economia tem como finalidade o saber usar bem a riqueza, isto é, ela é considerada superior porque é um exemplo de atividade cuja finalidade está em si mesma, em contraste com a crematística que tem como função adquirir e produzir bens; sua finalidade constitui apenas um meio para finalidade da economia." (TABOSA, 2007, p. 37)
} 
p. 305), a estabelecer um novo modelo ideológico que ultrapasse modelos antropocêntricos de uma relação de hierarquia entre o Estado e a natureza.

\section{CONSIDERAÇÕES FINAIS}

O problema do acesso à justiça tem demandado sérias especulações acerca de seu enfrentamento, tanto por parte de quem pensa as epistemologias do Direito, quanto por quem protagoniza as relações de poder nela inseridas.

Com a justiça ambiental não poderia ser diferente. O manejo da norma de Direito Ambiental, nas mais diversas demandas que acenam pedido de tutela daquela natureza, encontram óbices não só configurados pela própria relação de fratura entre o Direito e a política ambiental e o que ela revela em termos de sustentabilidade, mas também pela visão setorial do julgador que, reconhece o ambiente como pedaços seccionados que não se inter- relacionam.

Os achados processuais ora analisados servem para ilustrar tal realidade. As demandas ambientais que foram analisadas revelam uma atuação processual carecedora de uma perspectiva sustentável, que compreenda os princípios ambientais como mandados de otimização, como os melhores argumentos a serem esgrimidos frente a uma conduta jurídica sustentável e ambientalmente responsável.

Fossem tais demandas solucionados sobre uma base interpretativa comprometida com os princípios ambientais relacionados ao desenvolvimento sustentável, teríamos a utilização de valores e critérios jurídicos importantes para interpretar e aplicar as leis em prol das gerações futuras.

No primeiro caso, proposta ação civil pública, o julgador adotaria uma postura investigativa mais dinâmica, apta a uma instrução processual pertinente àquela índole processual, oferecendo uma resposta tempestiva e eficiente ao problema da criação extensiva de búfalos a comprometer o ecossistema da Baixada Maranhense.

No segundo caso, do mandado de segurança, mais proveitoso às questões ambientais seria o julgador, rompendo com o modo antropocêntrico de enfrentamento das causas ambientais, deixasse que a natureza peculiar do mandado de segurança conduzisse seu pronunciamento. Diz-se disto que, com relação à índole especial do procedimento, aquela tutela só poderia ter sido concedida caso a lei, indubitavelmente, a prescrevesse a seu demandante e, ademais, estivesse ele a sofrer ato de coação ilícita ou abuso de poder em detrimento daquela ordem legal. O caso não era este. 
A cultura humana, evidenciada pelos meandros processuais administrativos, não atendeu aos princípios da eficiência administrativa quando da solicitação das respectivas autorizações ambientais por parte do postulante e, por isto, o Estado-juiz, primando por esta mesma eficiência, endereçou ao ecossistema a responsabilidade sobre tal fato, ao autorizar que se concedesse ao reclamante o acesso ao uso dos recursos naturais, sem qualquer estudo de impacto, descuidado de um ambiente formado pelos dois componentes, cultural e natural, que não se dissociam.

As decisões analisadas serviram para revelar um espírito do que se chama de 'crematística processual', esta reconhecida em atos procedimentais formais de produção de numerário processual, alheio ao espírito de desenvolvimento com sustentabilidade.

Diante do que se verifica, há que decidir se um acesso à justiça mais eficiente e mais respeitoso do humano e da natureza, não seria preferível, à custa da desaceleração de seu ritmo utilitarista e não sustentável.

\section{REFERÊNCIAS}

ALEXY, Robert. Teoria da Argumentação Jurídica. Rio de janeiro: Forense, 2013. BEDAQUE, José Roberto dos Santos. Juiz, Processo e Justiça. In: Ativismo Judicial e Garantismo Processual. p. 111-146, Salvador: Editora JusPodivm, 2013.

BELLEN, Hans Michael Van. Desenvolvimento Sustentável: Uma Descrição das Principais Ferramentas de Avaliação. 73 Ambiente \& Sociedade - Vol. VI I no 1 jan./jun, p. 67-89, 2003. Disponível em < http://www.scielo.br/pdf/\%0D/asoc/v7n1/23537.pdf>. Acesso em 28 mar.2016.

BELLMONT, Yary Saidy. El concepto de justicia ambiental. In: Elementos para uma teoria de la Justicia Ambiental y el Estado Ambiental del Derecho. Colección Gerardo Molina. n 28, p. 63-113, set 2011. Bogotá: Universidad Nacional de Colombia. Facultad de Derecho, Ciencias Políticas y Sociales, 2012.

BRASIL. Constituição (1988). Constituição da República Federativa do Brasil. Brasília: Senado, 2009.

. Código de Processo Civil. Lei $\mathbf{n}^{\circ}$ 13.105, de 16 de março de 2015. Novo CPC. São Paulo: Saraiva, 2015.

Lei n ${ }^{\circ} 4.717$ de 29 de Junho de 1965. Regula a Ação Popular.1965.

Lei no 6.938 de 31 de agosto de 1981. Política Nacional do Meio Ambiente, fins e mecanismos de formulação. Senado Federal. Brasília, DF. v. I, 1981. 
. Lei 7.347 de 24 de julho de 1985. Lei de Ação Civil Pública. Brasília, DF: Senado Federal, 1985.

Lei 12.016, de 07 de agosto de 2009. Lei do Mandado de Segurança. Diário Oficial da República Federativa do Brasil, Poder Executivo, Brasília, DF, 8 ago. 2009.

CÂMARA, Alexandre Freitas. Poderes Instrutórios do Juiz e Processo Civil Democrático. In: Ativismo Judicial e Garantismo Processual. p. 65-78, Salvador: Editora JusPodivm, 2013.

CAPPELlETTI, Mauro; GARTH, Bryant. Acesso à justiça. Tradução Ellen Gracie Northfleet. Porto Alegre: Sérgio Antônio Fabris Editora, 2002.

CAVALCANTI, Clóvis. Concepções da economia ecológica: suas relações com a economia dominante e a economia ambiental. Estud. av. [online]. 2010, vol.24, n.68, p.5367. ISSN 0103-4014. Disponível em < http://dx.doi.org/10.1590/S010340142010000100007>. Acesso em 17.mar.2016.

DIDIER JR., Fredie. Curso de Direito Processual Civil, vol 1. Salvador: Jus Podivum, 2015.

MESA CUADROS, Gregório. Derechos ambientales en la perspectiva de integralidad: Concepto y fundamentacion de nuevas demandas y resistências actuales hacia el "Estado ambiental de derecho". $3^{\text {a }}$ ed. Bogotá: Universidad Nacional de Colombia. Faculdad de Derecho, Ciencias Políticas y Sociales, 2013.

MUNIZ, Lenir Moraes. A Criação de Búfalos na Baixada Maranhense: uma análise do desenvolvimentismo e suas implicações sócio-ambientais. Disponível em: <http://jurisconsult.tjma.jus.br/eNoFwYENgCAMXDCwX3hA5hQCHuAZZsyZkKCQIf_T9 uggGnzY75IkuRvIWvLsKGyI4mEVDNA0v5K1nkpj4fr1UX662kglM5ljAtpAFoM,\#todas_ movime >. Acesso em: 30 set. 2015.

NOHARA, Irene Patrícia. Direito Administrativo. São Paulo: Atlas, 2011.

RAMOS, Paulo Roberto Barbosa. O Conceito de Constituição em Lassale. Porto Alegre: Sérgio Antônio Fabris Editor, 2012.

RIBEIRO, Renato Janine. John Locke e o Individualismo Liberal. In: Os Clássicos da Política. Org. Francisco Weffort. Vol. 1, p. 61-75, $1^{\text {a }}$ Ed. São Paulo: Editora Ática, 2011.

ROULAND, Norbert. Nos Confins do Direito. São Paulo: Martins Fontes, 2008.

SANTOS, Boaventura de Sousa. Pela Mão de Alice: O Social e o Político na PósModernidade. São Paulo: Cortez, 2013.

Para uma Revolução Democrática da Justiça. São Paulo: Cortez, 2007.

SEN, Amartya. Desenvolvimento como Liberdade. São Paulo: Companhia das Letras, 2008.

. A Ideia de Justiça. São Paulo: Companhia das Letras, 2014.

TABOSA, Adriana S. O Problema da Análise Econômica em Aristóteles: Um estudo sobre 
a distinção dos conceitos de economia e crematística. 2007. 82 f. Dissertação (Mestrado em Filosofia) - Instituto de Filosofia e Ciências Humanas da Universidade Estadual de Campinas - UNICAMP, Campinas. $2007 . \quad$ Disponível em: <http://www.bibliotecadigital.unicamp.br/document/?code=vtls000406356\&fd=y $>\quad$ Acesso em: 27 set 2015 .

TEMER, Michel. Elementos de Direito Constitucional. São Paulo: Malheiros, 2010.

TJMA. Câmaras Cíveis Reunidas. Mandado de Segurança no 028392/2012. Relatora Desembargadora Ângela Maria Moraes Salazar. Acórdão 15/05/2015. Disponível em: http://jurisconsult.tjma.jus.br/eNo9i0sOgjAURbdi2EBLMEBxyMChkbiB2w_4TG1JP8TIW9 Q4O_fmnDjUQgxVg7njQrUN5NyrY6t7NC06qaXqZmgRzZKd9ueAzB45UFxcQ9bGKQJbs ZADq51MbvQuZpsQmPpTeqXxjs0wS6oUOOApybgEy6JVpdCk4Etf1iUsBfmOk7FIPjBet7z 5PDdaf9o1wyXS0Oa7XCezUdzd6vQGnq9JKQ,,> . Acesso em 30.set.2015

. Segunda Câmara Cível. Apelação Cível no 29.764/2012. Relator Desembargador
Vicente de Castro. http://jurisconsult.tjma.jus.br/eNoFwdsNgCAMBdBdWECTKi8HcI5LCwQ_0JR0f89ZYzZEVrYE3tCaZEPLxHkEYoUDg2SVu025b0Vtj2mY31qUlwnD7jrB62SFlwn> Acesso em 30.set.2015.

TJRS. Primeira Câmara Cível. Agravo de Instrumento $\mathbf{n}^{\mathbf{0}}$ 70063996649. Relator Desembargador Sergio Luiz Grassi Beck, Julgado em 07/05/2015. Disponível em: < http://tjrs.jusbrasil.com.br/jurisprudencia/188281182/agravo-de-instrumento-ai-70063996649-rs>.

Acesso em 18.março.2016.

TOCQUEVILle, Alexis de. A democracia na América: Leis e Costumes. São Paulo: Martins Fontes, 2005.

WOLKMER, Antônio Carlos. Introdução ao Pensamento Jurídico Crítico. São Paulo: Saraiva, 2010. 